ORIGINAL ARTICLE

\title{
Cost effectiveness analysis of neonatal extracorporeal membrane oxygenation based on four year results from the UK Collaborative ECMO Trial
}

\section{S Petrou, L Edwards}

Arch Dis Child Fetal Neonatal Ed 2004;89:F263-F268. doi: 10.1136/adc.2002.025635

See end of article for authors' affiliations a.t.

Correspondence to: Dr Petrou, National Perinatal Epidemiology Unit, Institute of Health Sciences, University of Oxford, Old Road, Headington, Oxford OX3 7LF, UK; stavros.petrou@ perinat.ox.ac.uk

Accepted 27 May 2003

\begin{abstract}
Objective: To assess the cost effectiveness of extracorporeal membrane oxygenation (ECMO) for mature newborn infants with severe respiratory failure over a four year time span.

Design: Cost effectiveness analysis based on a randomised controlled trial in which infants were individually allocated to ECMO (intervention) or conventional management (control) and then followed up to 4 years of age.

Setting: Infants were recruited from 55 approved recruiting hospitals throughout the United Kingdom. Infants allocated to ECMO were transferred to one of five specialist regional centres. Follow up of surviving infants was performed in the community.

Subjects: A total of 185 mature (gestational age at birth $\geqslant 35$ weeks, birth weight $\geqslant 2000 \mathrm{~g}$ ) newborn infants with severe respiratory failure (oxygenation index $\geqslant 40$ ).

Main outcome measures: Incremental cost per additional life year gained; incremental cost per additional disability-free life year gained.

Results: Over four years, the policy of neonatal ECMO was effective at reducing known death or severe disability (relative risk $=0.64 ; 95 \%$ confidence interval 0.47 to $0.86 ; p=0.004$ ). After adjustment for censoring and discounting at $6 \%$, the mean additional health service cost of neonatal ECMO was $£ 17367$ (95\% confidence interval $£ 12072$ to $£ 22224$ ) per infant (£UK, 2001 prices). Over four years, the incremental cost of neonatal ECMO was $£ 16707$ (£9828 to £37 924) per life year gained and £24 775 (£13 106 to $£ 69690$ ) per disability-free life year gained. These results remained robust after variations in the values of key variables performed as part of a sensitivity analysis.

Conclusions: The study provides rigorous evidence of the cost effectiveness of ECMO at four years for mature infants with severe respiratory failure.
\end{abstract}

$\mathrm{N}$ eonatal extracorporeal membrane oxygenation (ECMO) is a complex technique for providing life support to critically ill newborn infants who develop acute, but potentially reversible, respiratory failure. ${ }^{1}$ The technique oxygenates blood outside the body, thereby obviating the need for gas exchange in the lungs and, if necessary, can also assist cardiovascular circulation. ${ }^{2}$ Early claims that neonatal ECMO is more effective than less invasive forms of life support were based on case series and on studies with historical controls. ${ }^{3}$ These studies suggested that neonatal ECMO substantially reduces the risk of death, but were conducted at a time when background neonatal death rates were falling. ${ }^{45}$ Three small randomised controlled trials of neonatal ECMO were conducted during the 1980s and early 1990s, ${ }^{6-9}$ all of which suggested that the technique reduces the risk of death in mature infants with severe respiratory failure. However, these trials were subject to a number of methodological limitations. The adaptive designs applied by the first two trials ${ }^{6}{ }^{7}$ meant that very few infants were allocated to conventional management, and the third trial $^{8}{ }^{9}$ has been reported only as conference abstracts.

As an expensive new technology in limited use outside of the United States, neonatal ECMO was suitable for evaluation under the United Kingdom (UK) health technology assessment model in the NHS research initiative. ${ }^{10}$ As a consequence, the UK Collaborative ECMO Trial was initiated in 1993. A prospective economic evaluation was incorporated into the trial design with the view to establishing the cost effectiveness of the technique. The clinical and economic results of the trial observed over a one year follow up period were reported in the late 1990s, ${ }^{11}$ and the substantive long term outcomes were reported in 2001. ${ }^{12}$ In this paper, we report the cost effectiveness of neonatal ECMO based on results from the randomised controlled trial observed over a four year follow up period.

\section{METHODS}

Trial background

A pragmatic randomised controlled trial was conducted to evaluate the benefits and risks associated with neonatal ECMO. Mature (gestational age at birth $\geqslant 35$ weeks, birth weight $\geqslant 2000 \mathrm{~g}$ ) newborn infants with severe respiratory failure (oxygenation index $\geqslant 40^{13}$ ) were randomised in the trial. The infants were recruited from 55 centres throughout the United Kingdom between January 1993 and November 1995. Each of these centres was accustomed to providing long term ventilatory support for newborn infants under the care of a paediatrician specialising in neonatology, with 24 hour availability of facilities for invasive blood pressure monitoring and cranial ultrasound. Infants allocated to the ECMO group were transferred, by air or road, to one of five specialist regional centres where they were cannulated, and ECMO support was started according to a specified protocol. Infants allocated to the conventional management group continued to receive intensive conventional care in the recruiting centre, based on trial guidelines for continued ventilation. The primary outcomes of the trial were death and long term

Abbreviations: ECMO, extracorporeal membrane oxygenation; QALYs, quality adjusted life years 
morbidity, which was assessed in a preliminary form at 1 year of age, ${ }^{1}$ and then more fully at 4 years of age. ${ }^{12}$ Standardised neurodevelopmental assessments were performed in the homes of the surviving infants by a single paediatrician within two weeks of their fourth birthday. Outcome status was assessed across six clinical domains (cognitive ability, neuromotor skills, general health, behaviour, vision, and hearing), each of which was defined as normal, impaired, mildly disabled, moderately disabled, or severely disabled on the basis of the degree of functional loss. A child's overall disability status was defined by the highest degree of disability in any of the six clinical domains. The individual measures used to assess outcomes, the definitions of impairment and functional disability for each clinical domain, as well as broader information on the clinical assessment and validation exercises are reported elsewhere. ${ }^{14}$

\section{Type of evaluation, perspective, and time horizon}

An incremental cost effectiveness analysis was performed in which we calculated the incremental costs and incremental effectiveness of neonatal ECMO compared with conventional management, and expressed these as a ratio. The economic evaluation was conducted from a health service perspective and therefore only direct costs to NHS hospital and community providers were included. ${ }^{15}$ The time horizon for the economic evaluation was the four year duration of the clinical study.

\section{Resource use data}

Data were collected about all major health service resource inputs during the study period. Resource inputs were divided into seven categories: those attributable to $(a)$ air and road transportation, $(b)$ the initial hospital admission, (c) the death of the infant, (d) hospital readmissions, $(e)$ hospital outpatient care, $(f)$ community health care, and $(g)$ other healthcare services.

As part of the trial data collection forms, a record was kept of the mode of transport (road ambulance, fixed wing aircraft, or helicopter), duration of transportation and distances travelled by the infant, initially to the referral centre to receive their allocated care and subsequently back to an appropriate local hospital before discharge.

The infant's initial stay in hospital was described by one of the following five mutually exclusive levels of care known to carry different $\operatorname{costs}^{16}:(a)$ days receiving neonatal ECMO; $(b)$ days receiving maximal intensive care (more than $90 \%$ oxygen); (c) days on a ventilator (receiving less than $90 \%$ oxygen); (d) days on supplementary oxygen; (e) days in normal care.

Observational work was undertaken to estimate the resource inputs associated with an infant death. These included the resource inputs associated with the postmortem examination and associated procedures, and those associated with the transportation of the deceased infant home in an ambulance.

Data on use of health service resources by each infant after their initial discharge from hospital were obtained during the course of four interviews with the parents. Three interviews were held over the telephone at 4 months, 8 months, and 12 months, and a face to face interview was held at 4 years. The first three interviews recorded total hospital and community health service use over the preceding four month period. The interview conducted at 4 years was divided into two parts. Firstly, it asked a series of questions about the child's use of inpatient and outpatient hospital services since their first birthday, including the name of the hospital provider, its location, the duration of contact, and the ward or clinic attended. Secondly, it asked a series of questions about the child's use of community health services over the preceding six months, including the professional agency that provided the service; its location; the frequency of use; the duration of each service contact; as well as the degree to which the use of each community service had changed compared with previous periods. To validate the information provided at 4 years, the general practitioner of each child was asked to provide a detailed profile of the child's attendances and prescriptions, as well as referrals to hospital and other community health service providers. In addition, the other health service providers identified by the parents were contacted, first by letter and where necessary by telephone, and asked to provide a detailed profile of the care that they had provided to the child since its first birthday.

\section{Unit costs}

Unit costs for resources used by the trial participants were obtained from a variety of sources. All unit costs used followed recent guidelines on costing healthcare services as part of economic evaluation. ${ }^{15}{ }^{17}$ An average cost per neonatal ECMO day was calculated by sending each specialist regional centre a detailed questionnaire, requesting cost data for the main resource categories of drugs, disposables, equipment, staff, and overheads, and then apportioning these to different categories of patient using "top down" methodology. ${ }^{11}$ Each specialist regional centre was visited to ensure consistency in the apportionment and reporting of cost data. An average cost per day for each level of non-ECMO conventional neonatal care was derived from estimates from a separately funded study ${ }^{18}$ which had been weighted by a factor of $10 \%$ to take account of the size and case mix of the units participating in the trial. ${ }^{11}$ Road ambulance costs were obtained from the London Ambulance Service and incorporated a fixed fee for the vehicle, a rate for mileage, and an hourly rate for the total time the ambulance was in use, and air transport costs were obtained from the records of the relevant providers. The cost of postmortem examinations was obtained from local pathologists. Specialty based daily costs for each type of hospital readmission and average costs for each type of outpatient visit were based on the UK Department of Health's NHS Trust Financial Returns (TFR2). The unit costs of community health services were largely derived from national sources, ${ }^{19}$ although some were calculated from first principles using established accounting methods.$^{20}$ The cost of drugs prescribed by general practitioners was obtained from the British National Formulary. Unit costs were combined with resource volumes to obtain a net cost per infant during the trial period. All costs are expressed in UK pounds sterling and valued at 2001 prices.

\section{Representation of cost effectiveness}

The cost effectiveness of neonatal ECMO was expressed in two forms: $(a)$ in terms of incremental cost per additional life year gained; $(b)$ in terms of incremental cost per additional disability-free life year gained. For the former measure, the date of death was obtained, where necessary, from health service providers. For the latter measure, the period of survival for infants whose overall disability status was not classified as either impaired or disabled was estimated in terms of disability-free life years, thereby obviating the need for subjective valuations for each state of impairment or disability. The probability that neonatal ECMO is cost effective at 4 years at different values for the willingness of the NHS to pay for an additional life year and for an additional disability-free life year is represented by cost effectiveness acceptability curves. ${ }^{21}$ For the purposes of our analysis, we have indicated these probabilities at an NHS willingness to pay threshold of $£ 30000$ for each outcome. ${ }^{22}$ 


\section{Data analysis}

The statistical approach developed by Lin $e t a^{23}$ was used to simulate costs for five infants who were lost to follow up during the course of the study and whose information could therefore be described as censored. Costs and health effects accruing beyond the first year were reduced to present values using the discount rates currently recommended for the UK public sector, namely $6 \%$ for costs and $1.5 \%$ for health effects. ${ }^{24}$

All results are reported as means (SD) and as mean differences in costs and effects with $95 \%$ confidence intervals (CIs) where applicable. We tested for differences between the trial groups using Student's $t$ test and considered those differences significant if two tailed p values were 0.05 or less. As the data for costs were skewed, we used non-parametric bootstrap estimation to derive $95 \%$ CIs for mean cost differences between the groups. ${ }^{25}$ Each of these confidence intervals was calculated using 1000 bias corrected bootstrap replications. Non-parametric bootstrap methods were also used to calculate 95\% CIs for incremental cost effectiveness ratios. ${ }^{26}$ All analyses were performed with a microcomputer running Statistical Package for the Social Sciences software.

\section{Sensitivity analysis}

A series of multiway sensitivity analyses was undertaken to explore the implications of uncertainty on the base case incremental cost effectiveness ratios. ${ }^{27}$ Changes in the values of three key variables were considered as part of the sensitivity analyses. Firstly, two alternative scenarios of daily costs for each level of neonatal care were tested in order to reflect variations in the relative price structures of resource inputs across hospital settings. ${ }^{28}$ In scenario 1 , the daily costs for each level of neonatal care were assumed to be $20 \%$ less than those generated by our accounting methods, whereas, in scenario 2, they were assumed to be $20 \%$ greater. Secondly, three alternative scenarios of community service use were tested in response to a tendency, on the part of participants in health economic studies, to underreport numbers of community service contacts. ${ }^{29}$ In scenario 1 , community service use by the children was assumed to be $10 \%$ greater than reported by the parents. In scenario 2 , community service use was assumed to be $20 \%$ greater, and in scenario 3 , community service use was assumed to be $30 \%$ greater. Finally, to reflect differing views in the health economics literature on the appropriate discount rates for costs and health effects, ${ }^{15} 3031$ the discount rate that was applied to costs was varied to $0 \%, 3 \%$, and $10 \%$, and the discount rate that was applied to health effects was varied to $0 \%, 3 \%$, and $6 \%$.

\section{RESULTS}

Resource use and clinical effectiveness data were collected for 185 infants who were randomly allocated to either the ECMO group ( $\mathrm{n}=93$ ) or the conventional management group $(n=92)$. The clinical results of the trial are outlined in detail in the main clinical papers. ${ }^{12}$ In brief, by 4 years of age, neonatal ECMO had increased the number of survivors $(62 v$ 38 ) and the number of survivors who were formally classified as free of disability $(30 \vee 13)$ (table 1). However, it also increased the number of survivors with severe disability $(3 v$ $0)$. Overall, the policy of neonatal ECMO was effective at reducing known death or severe disability at 4 years: 34 of 93 $(37 \%)$ in the ECMO group $v 54$ of $92(59 \%)$ in the conventional management group (relative risk $=0.64 ; 95 \%$ CI 0.47 to $0.86 ; \mathrm{p}=0.004$ ).

\section{Resource use}

Table 2 shows the use of healthcare resources by the trial groups and the associated unit costs for each resource item.
Table 1 Short and long term outcomes for infants randomised in UK Collaborative ECMO Trial

\begin{tabular}{|c|c|c|}
\hline & $\begin{array}{l}\text { ECMO } \\
(\mathrm{n}=93)\end{array}$ & $\begin{array}{l}\text { CM } \\
\text { (n = 92) }\end{array}$ \\
\hline \multicolumn{3}{|l|}{ Deaths } \\
\hline Before discharge & $28(30)$ & $54(59)$ \\
\hline Between discharge and 1 year & $2(2)$ & $0(0)$ \\
\hline Between 1 and 4 years & $1(1)$ & $0(0)$ \\
\hline Total & $31(33)$ & $54(59)$ \\
\hline \multicolumn{3}{|l|}{ Loss to follow up } \\
\hline Between discharge and 1 year & $1(1)$ & $1(1)$ \\
\hline Between 1 and 4 years & $1(1)$ & $2(2)$ \\
\hline Total & $2(2)$ & $3(3)$ \\
\hline \multicolumn{3}{|l|}{ Final assessment at 4 years of age } \\
\hline Severe disability & $3(3)$ & $0(0)$ \\
\hline Moderate disability & $9(10)$ & $10(11)$ \\
\hline Mild disability & $18(19)$ & $12(13)$ \\
\hline Impairment only & 18 (19) & $9(10)$ \\
\hline No abnormal signs or disability & $12(13)$ & $4(4)$ \\
\hline Known survivors with no disability & $30 / 60(50)$ & $13 / 35(37)$ \\
\hline
\end{tabular}

Values in parentheses are percentages.

ECMO, Extracorporeal membrane oxygenation; $\mathrm{CM}$, conventional management.

Infants allocated to the ECMO group spent, on average, significantly more days receiving normal care and overall hospital care than infants allocated to the conventional management group $(\mathrm{p}<0.05)$. They also made significantly more ambulance journeys, outpatient hospital visits, and health visitor visits $(\mathrm{p}<0.05)$. In contrast, infants allocated to the conventional management group spent, on average, significantly more days receiving maximal intensive care than infants allocated to the ECMO group $(p<0.05)$. There were no significant differences in the use of other healthcare resource items between the trial groups.

\section{Costs}

Neonatal ECMO increased the cost of transportation by an average of $£ 1674(p<0.0001)$ compared with conventional management (table 3 ). Similarly, neonatal ECMO increased the cost of the initial hospital stay by an average of $£ 15248$ ( $p<0.0001)$, and the cost of outpatient hospital care by an average of $£ 226$ ( $p=0.002$ ) compared with conventional management. The greater number of deaths in the conventional management group meant that the costs associated with the death itself were, on average, $£ 372$ higher $(p<0.0001)$ in the conventional management group. Statistical analysis revealed that, at the $5 \%$ level, there were no significant differences in the mean cost of inpatient hospital readmissions, community care, and other health services between the two trial groups. The net trial costs per subject of the two groups were £26 053 in the ECMO group and $£ 8686$ in the conventional management group, providing a mean cost difference of $£ 17367$ $(\mathrm{p}<0.0001)$.

\section{Incremental cost effectiveness}

The incremental cost per additional life year gained was estimated at £16 707, and the incremental cost per additional disability-free life year gained was estimated at $£ 24775$ (table 4). Figure 1 gives cost effectiveness acceptability curves for the principal outcome measures. At the notional willingness to pay threshold of $£ 30000$ for an additional life year, the probability that neonatal ECMO is cost effective at 4 years was estimated at 0.94. Similarly, at the notional willingness to pay threshold of $£ 30000$ for an additional disability-free life year, the probability that neonatal ECMO is cost effective at 4 years was estimated at 0.69 . 
Table 2 Resource use and unit costs of resource items (UK£ sterling, 2001 prices)

\begin{tabular}{|c|c|c|c|}
\hline \multirow[b]{2}{*}{ Resource use variable } & \multicolumn{2}{|c|}{ Resource use value } & \multirow[b]{2}{*}{ Unit cost or range* } \\
\hline & ECMO $(n=93)$ & $\mathrm{CM}(\mathrm{n}=92)$ & \\
\hline \multicolumn{4}{|l|}{ Initial hospital stay } \\
\hline Days on ECMO & $5.67(5.49)$ & $0.24(2.29)$ & 2179.2 per day $\dagger$ \\
\hline Days on $>90 \%$ oxygen & $1.48(3.07)$ & $3.56(4.40)$ & 237.4-264.6 per day $\dagger$ \\
\hline Days on ventilator & 6.25 (13.72) & $3.95(8.55)$ & 237.4-264.6 per dayt \\
\hline $\begin{array}{l}\text { Days on supplemental oxygen at } \\
\text { any concentration }\end{array}$ & $15.91(39.84)$ & $8.87(37.65)$ & 237.4-264.6 per dayt \\
\hline Days on normal care & $10.32(19.29)$ & $4.23(7.99)$ & 237.4-264.6 per day $\dagger$ \\
\hline Total days in hospital & $39.62(58.43)$ & $20.85(45.10)$ & \\
\hline Number of ambulance journeys & $1.90(1.30)$ & $0.43(0.65)$ & 199.3-10150.1 per journey† \\
\hline \multicolumn{4}{|l|}{ After initial hospital stay } \\
\hline $\begin{array}{l}\text { Number of days of inpatient } \\
\text { hospital readmissions }\end{array}$ & $4.02(12.24)$ & $3.03(8.18)$ & 353.0 per day $\ddagger$ \\
\hline Number of outpatient hospital visits & $4.60(6.03)$ & $2.35(3.58)$ & 57.0-104.0 per visitł \\
\hline $\begin{array}{l}\text { Number of visits to general } \\
\text { practitioner }\end{array}$ & $16.44(24.59)$ & $10.47(19.80)$ & 26.0-59.0 per contact hourf \\
\hline Number of health visitor visits & $10.51(11.28)$ & $7.18(11.34)$ & 30.0-72.0 per contact hour $\ddagger$ \\
\hline $\begin{array}{l}\text { Number of visits to other } \\
\text { community carers }\end{array}$ & $6.35(21.25)$ & $17.86(83.51)$ & 11.6-85.0 per contact hour $\$ \S^{\star *}$ \\
\hline Death & - & - & 1304.0 per death $\dagger$ \\
\hline
\end{tabular}

Resource use values are given as mean (SD).

ECMO, Extracorporeal membrane oxygenation; $\mathrm{CM}$, conventional management.

*Ranges of unit costs are specified where unit costs varied according to type or intensity of care provided.

†Roberts et al. ${ }^{1}$

$\ddagger$ Netten et al. ${ }^{19}$

§Primary research.

- Inclusive of $£ 104.0$ per paediatric visit, $£ 57.0$ per surgical visit, $£ 75.0$ per cardiology visit, $£ 57.0$ per

dermatology visit, and £61.0 per accident and emergency visit.

**Inclusive of $£ 85.0$ per community paediatrician contact hour, $£ 11.6$ per community nurse contact hour, $£ 38.0-$ $£ 49.0$ per physiotherapist contact hour, $£ 41.0$ per occupational therapist contact hour, $£ 41.0$ per speech therapist contact hour, £36.0 per psychologist contact hour, £28.5 per counsellor contact hour, $£ 85.0$ per ophthalmologist contact hour, $£ 49.0$ per optometrist contact hour, $£ 39.0$ per orthoptist contact hour, and $£ 37.0$ per audiologist contact hour.

\section{Sensitivity analysis}

Table 4 shows the results of the sensitivity analysis. A $20 \%$ reduction and increase in the daily cost for inpatient care had the effect of respectively reducing and increasing the incremental cost per additional life year gained by $£ 2994$ and the incremental cost per additional disability-free life year gained by $£ 4440$. The assumption that community service use was $10 \%$ greater than reported by the parents had the effect of increasing the incremental cost per life year gained by $£ 25$ and the incremental cost per disability-free life year gained by $£ 37$. The respective increases in the incremental cost effectiveness ratios were $£ 50$ and $£ 75$ when community service use was $20 \%$ greater than reported by the parents, and $£ 75$ and $£ 112$ when community service use was $30 \%$ greater than reported by the parents. Finally, variations in the rate at which costs were discounted had a minimal effect, whereas applying a $6 \%$ discount rate to health effects increased the incremental cost per additional life year gained by $£ 1751$ and the incremental cost per disability-free life year gained by $£ 2793$.

\section{DISCUSSION}

The strengths of the trial on which this economic evaluation was based are that it was randomised and controlled, pragmatic in design, and provided a vehicle for collecting a comprehensive set of data on resource use and clinical effectiveness. These provide a reliable basis for estimating the economic efficiency of neonatal ECMO for mature infants with severe respiratory failure. The study cost accounting was comprehensive and included all major health service cost items.

The economic evaluation showed that a policy of neonatal ECMO significantly increases neonatal costs and, if adopted, will increase overall health service costs during the first 4 years of life. Because the trial also showed that this technology is more clinically effective, decision making bodies may be aided in their decisions about the technology by the economic information generated by this study. Decision making bodies that are considering adopting or increasing the diffusion of the technology may be informed by the incremental cost effectiveness ratios for the principal

Table 3 Mean costs and mean cost differences by cost category (UK£ sterling, 2001 prices)

\begin{tabular}{|c|c|c|c|c|c|c|c|}
\hline \multirow[b]{2}{*}{ Cost category } & \multicolumn{2}{|c|}{$\mathrm{ECMO}(\mathrm{n}=93$ ) } & \multicolumn{2}{|c|}{$\mathrm{CM}(\mathrm{n}=92)$} & \multirow[b]{2}{*}{ Mean difference } & \multirow[b]{2}{*}{ p Value } & \multirow[b]{2}{*}{ Bootstrap mean difference $195 \% \mathrm{Cl}$} \\
\hline & Mean & SD & Mean & SD & & & \\
\hline Death & 393 & 601 & 765 & 646 & -372 & $<0.0001$ & $-377(-543$ to -203$)$ \\
\hline Transport & 1942 & 2787 & 268 & 703 & 1674 & $<0.0001$ & 1664 (1126 to 2253 ) \\
\hline Initial hospital stay & 20806 & 19559 & 5558 & 11892 & 15248 & $<0.0001$ & 15164 (10499 to 19785$)$ \\
\hline Readmissions & 1157 & 3244 & 829 & 2317 & 328 & 0.430 & $345(-472$ to 1230$)$ \\
\hline Outpatient care & 462 & 589 & 236 & 355 & 226 & 0.002 & 226 (95 to 366$)$ \\
\hline Community care & 1270 & 1471 & 1019 & 2243 & 251 & 0.369 & $256(-352$ to 730$)$ \\
\hline Other health service costs & 23 & 134 & 11 & 53 & 12 & 0.420 & $12(-12$ to 46$)$ \\
\hline Total NHS costs & 26053 & 21058 & 8686 & 15489 & 17367 & $<0.0001$ & 17321 (12072 to 22224$)$ \\
\hline
\end{tabular}

$\mathrm{p}$ Values were calculated using Student's $t$ test. Non-parametric bootstrap estimation was performed using 1000 replications, bias corrected. ECMO, Extracorporeal membrane oxygenation; $\mathrm{CM}$, conventional management. 


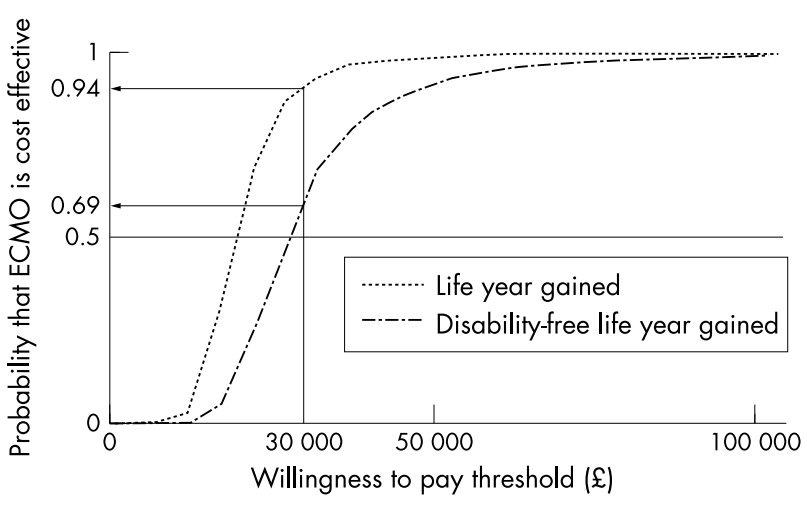

Figure 1 Cost effectiveness acceptability curves. Probability that neonatal extracorporeal membrane oxygenation (ECMO) is cost effective after four years plotted as a function of NHS willingness to pay per unit of outcome.

outcomes. Furthermore, jurisdictions where the technology is already established may be able to incorporate our estimates of the resource consequences of neonatal ECMO support into their service planning.

The incremental cost per additional life year gained was estimated at $£ 16707$, and the incremental cost per additional disability-free life year gained was estimated at $£ 24775$, both of which remained robust after variations in the values of key variables performed as part of sensitivity analyses. Moreover, to make comparisons with other healthcare technologies, ${ }^{32}$ our estimates of cost effectiveness have been mapped against alternative willingness to pay thresholds for each unit of outcome. As a result, we have attempted to handle both levels of uncertainty surrounding the baseline cost effectiveness ratios, uncertainty surrounding our estimated variable values, and uncertainty surrounding the ceiling cost effectiveness ratio that a decision maker would consider acceptable. ${ }^{33}$

The study does have caveats, which should be borne in mind. Firstly, the difference in costs and outcomes between the two trial arms could be overestimates if they reflect greater experience and service infrastructure within the ECMO specialist centres, rather than an effect of ECMO itself. To guard against this potential bias, hospitals providing conventional management in the trial had to meet criteria indicating substantial experience and service infrastructure in providing neonatal ventilatory care. ${ }^{1}$ Secondly, by adopting a health service perspective, the study has excluded the costs borne by other sectors of the economy, the costs borne by parents or informal carers, and the costs of lost production. Measurement and valuation of these wider societal costs may increase the incremental cost of achieving each unit of outcome, because the increased chances of survival resulting from neonatal ECMO will necessitate broader resource use. Thirdly, the effectiveness of neonatal EMO has not been measured in terms of quality adjusted life years (QALYs) gained, a single metric that incorporates societal preferences for each possible health outcome, ${ }^{34}$ and which is therefore more useful for comparative purposes. ${ }^{24}$ The health related quality of life of the trial survivors is currently being assessed as part of a follow up study at 7 years, and it is expected that this will provide a basis for estimating an incremental cost utility ratio for neonatal ECMO. Fourthly, the four year time frame for this analysis is likely to have underestimated the long term cost effectiveness of neonatal ECMO, as the survival advantage from the 24 additional survivors related to neonatal ECMO up to 4 years will continue to generate additional life years and QALYs after four years. We are hesitant to project a lifetime cost effectiveness or cost utility
Table 4 Incremental cost effectiveness ratios (UK£ sterling, 2001 prices)

\begin{tabular}{|c|c|c|}
\hline Cost and outcome measure & Mean & $95 \% \mathrm{Cl}^{*}$ \\
\hline \multicolumn{3}{|l|}{$\begin{array}{l}\text { Sensitivity analyses for principal outcome } \\
\text { (a) Hospital costs }\end{array}$} \\
\hline (1) $20 \%$ reduction in daily costs & 13713 & 7792 to 31916 \\
\hline $\begin{array}{l}\text { (2) } 20 \% \text { increase in daily cost } \\
\text { (b) Community service use }\end{array}$ & 1 & 11327 to 46923 \\
\hline (1) $10 \%$ greater than reported & 16732 & 41649 \\
\hline & & 3593 \\
\hline & 16782 & 9849 to 38839 \\
\hline \multicolumn{3}{|l|}{ (c) Discount rates applied to years $1-4$} \\
\hline (1) Costs discounted at $0 \%$ & 16716 & $10240 t$ \\
\hline & & 386 \\
\hline & 16712 & 9911 \\
\hline & 16101 & 9406 \\
\hline & 172 & 38602 \\
\hline (6) Life years disc & 18 & 0623 \\
\hline \multicolumn{3}{|l|}{$\begin{array}{l}\text { Sensitivity analyses for secondary outcome } \\
\text { (a) Hospital costs }\end{array}$} \\
\hline (1) $20 \%$ reduction in daily costs & 203 & 5870 \\
\hline (2) $20 \%$ inc & 29 & 4105 \\
\hline (1) $10 \%$ & 248 & 13 \\
\hline & & 0149 \\
\hline (3) $30 \%$ greater than reported & 24887 & 72299 \\
\hline \multicolumn{3}{|l|}{ (c) Discount rates applied to years 1-4 } \\
\hline (1) Costs discounted at $0 \%$ & 24789 & 989 \\
\hline $3 \%$ & 24787 & 4445 \\
\hline$+10 \%$ & 24783 & 13700 to 70811 \\
\hline $\begin{array}{l}\text { (4) Disability-free life years } \\
\text { discounted at } 0 \%\end{array}$ & 23879 & 12098 to 73504 \\
\hline $\begin{array}{l}\text { (5) Disability-free life years } \\
\text { discounted at } 3 \%\end{array}$ & 25697 & 138 \\
\hline $\begin{array}{l}\text { (6) Disability-free life years } \\
\text { discounted at } 6 \%\end{array}$ & 27568 & 15045 to 90608 \\
\hline
\end{tabular}

*Non-parametric bootstrap estimation was performed using 1000 replications, bias corrected.

ratio for neonatal ECMO at this stage, because that will necessarily be based on limited evidence. Rather, it is expected that a lifetime economic evaluation of neonatal ECMO will be conducted on completion of the seven year follow up study. Fifthly, statements on the relative cost effectiveness of neonatal ECMO are dependent on arbitrary NHS willingness to pay thresholds for health gains. We have estimated the probability that neonatal ECMO is cost effective against a threshold of $£ 30000$ for each outcome, reflecting the perceived current threshold value per QALY in the United Kingdom. ${ }^{22}$ However, it is conceivable that decision makers place a greater value on health gains experienced by the young than those experienced by other groups of the population. If this were the case, then the probability that neonatal ECMO is considered cost effective would be greater than we have reported.

In conclusion, our study provides rigorous evidence of the cost effectiveness of neonatal ECMO at 4 years for mature infants with severe but potentially reversible respiratory failure. It is incumbent on decision makers to decide whether the study results are applicable to their own settings and, if so, the likely economic impacts of their implementation.

\section{ACKNOWLEDGEMENTS}

We thank Tracey Roberts from the University of Birmingham for the primary cost fieldwork that she conducted at the ECMO centres. The UK Collaborative ECMO Trial and the economic evaluation were funded by the England and Wales Department of Health, Chief Scientist's Office, and the Scottish Office Department of Health. The views expressed by the authors do not necessarily reflect those of the funding bodies. 
Authors' affiliations

S Petrou, L Edwards, National Perinatal Epidemiology Unit, University of Oxford, Oxford, UK

\section{REFERENCES}

1 UK Collaborative ECMO Trial Group. UK collaborative randomised trial of neonatal extracorporeal membrane oxygenation. Lancet 1996:348:75-82.

2 Stolar CJ, Snedecor SM, Bartlett RH. Extracorporeal membrane oxygenation and neonatal respiratory failure: experience from the Extracorporeal Life Support Organization. J Pediatr Surg 1991;26:563-71.

3 Elboune D, Field D, Mugford M. Extracorporeal membrane oxygenation for severe respiratory failure in newborn infants. Cochrane Library, Issue 4. Oxford: Update Soffware, 2002.

4 Editorial. Persistent fetal circulation and extracorporeal membrane oxygenation. Lancet 1988;ii: 1289-91.

5 Dworetz AP, Moya FR, Sabo B, et al. Survival of infants with persistent pulmonary hypertension without extracorporeal membrane oxygenation. Pediatrics 1989;84:1-6.

6 O'Rourke PP, Crone RK, Vacanti JP, et al. Extracorporeal membrane oxygenation and conventional medical therapy in neonates with persistent pulmonary hypertension of the newborn: a prospective randomised study. Pediatrics 1989;84:957-63.

7 Bartlett RH. Extracorporeal life support for cardiopulmonary failure. Curr Probl Surg 1990;27:621-705.

8 Bifano EM, Hakanson DO, Hingre RV, et al. Prospective randomized controlled trial of conventional treatment or transport for ECMO in infants with persistent pulmonary hypertension (PPHN) [abstract]. Pediatr Res 1992;31:196A.

9 Gross SJ, Bifano EM, Gugenio D, et al. Prospective randomized controlled trial of conventional treatment or transport for ECMO in infants with severe persistent pulmonary hypertension (PPHN): two year follow up [abstract]. Pediatr Res 1994;36:17A.

10 Peckham M. Research and development for the National Health Service. Lancet 1991:338:367-71

11 Roberts TE and the ECMO Economics Working Group. Economic evaluation and randomised controlled trial of extracorporeal membrane oxygenation: UK Collaborative Trial. BMJ 1998;317:911-15.

12 Bennett CC, Johnson A, Field D, et al. UK collaborative randomised trial of neonatal extracorporeal membrane oxygenation: follow-up to age 4 years. Lancet 2001;357:1094-6.

13 Hallman M, Merritt A, Harvenpaa AL. Exogenous human surfactant for treatment of severe respiratory distress syndrome: a randomised prospective trial. J Pediatr 1985;106:963-9.

14 Bennett CC. Long-term morbidity in survivors of a randomised controlled trial of neonatal extracorporeal membrane oxygenation within the United Kingdom: Follow-up at four years of age. MD thesis, University of London, January 2002.
15 Drummond MF O'Brien B, Stoddart GL, et al. Methods for the economic evaluation of health care programmes, 2nd ed. Oxford: Oxford University Press, 1997.

16 Petrou S, Davidson LL. Economic issues in the follow-up of neonates. Semin Neonatol 2000:5:159-69.

17 Drummond MF, Jefferson TO. on behalf of the BMJ Economic Evaluation Working Party. Guidelines for authors and peer reviewers of economic submissions to the BMJ. BMJ 1996;313:275-83

18 O'Neill C, Malek M, Mugford M, et al. A cost analysis of neonatal care in the UK: results from a multicentre study. J Publ Health Med 2002;22:108-15.

19 Netten A, Rees T, Harrison G. Unit costs of health and social care. Canterbury: Personal Social Services Research Unit, University of Kent, 2001.

20 Allen C, Beecham J. Costing services: ideals and reality. In: Netten A, Beecham J, eds. Costing community care: theory and practice. Aldershot: Ashgate Publishing Ltd, 1993:25-42.

21 Lothgren $M$, Zethraeus N. Definition, interpretation and calculation of costeffectiveness acceptability curves. Health Econ 2000;9:623-30.

22 Raftery J. NICE: faster access to modern treatments? Analysis of guidance on health technologies. BMJ 2001;323:1300-3.

23 Lin DY, Feuer EJ, Etzioni R, et al. Estimating medical costs from incomplete follow-up data. Biometrica 1997;53:113-28.

24 National Institute for Clinical Excellence. Technical guidance for manufacturers and sponsors on making a submission to technology appraisal. London: National Institute for Clinical Excellence, 2001.

25 Barber JA, Thompson SG. Analysis of cost data in randomized trials: an application of the non-parametric bootstrap. Stat Med 2000;19:3219-36.

26 Briggs AH, Gray AM. Handling uncertainty when performing economic evaluation of healthcare interventions. Health Technol Assess 1999:3:1-134.

27 Briggs A, Sculpher M. Sensitivity analysis in economic evaluation of health care technologies: the role of sensitivity analysis. Health Econ 1995:4:355-72.

28 Drummond MF. Cost-effectiveness guidelines for reimbursement of pharmaceuticals: is economic evaluation ready for its enhanced status? Health Econ 1992;1:85-92.

29 Petrou S, Murray L, Cooper P, et al. The accuracy of self-reported health care resource utilization in health economic studies. Int J Technol Assess Health Care 2002; 18:705-10.

30 Parsonage $M$, Neuberger $\mathrm{H}$. Discounting and health benefits. Health Econ 1992;1:71-6.

31 Brouwer W, van-Hout B, Rutten F. A fair approach to discounting future effects: taking a societal perspective. J Health Serv Res Policy 2000:5:1 14-18.

32 Laupacis A, Feeny D, Detsky AS, et al. How attractive does a new technology have to be to warrant adoption and utilization? Tentative guidelines for using clinical and economic evaluations. Can Med Assoc J 1992;146:473-81

33 UK Prospective Diabetes Study Group. Cost-effectiveness analysis of improved blood pressure control in hypertensive patients with type 2 diabetes: UKPDS 40. BMJ 1998;317:720-6.

34 Torrance GW, Feeny D. Utilities and quality-adjusted life years. Int J Technol Assess Health Care 1989:5:559-75. 